\title{
Suprabenthic fauna from the Bellingshausen Sea and western Antarctic Peninsula: spatial distribution and community structure
}

\author{
CARLOS SAN VICENTE ${ }^{1}$, TOMAS MUNILLA ${ }^{2}$, JORDI CORBERA ${ }^{3}$, \\ JEAN-CLAUDE SORBE ${ }^{4}$ and ANA RAMOS ${ }^{5}$ \\ ${ }^{1}$ Carrer Nou, 8, E-43839 Creixell, Tarragona, Spain. \\ ${ }^{2}$ Laboratorio de Zoología, Dpto. de Biología Animal, Fac. Ciencias Biológicas. Universidad Autónoma de Barcelona, \\ E-08193 Barcelona, Spain. \\ ${ }^{3}$ Carrer Gran, 90, E-08310 Argentona, Catalonia, Spain. \\ ${ }^{4}$ Laboratoire d'Océanographie Biologique, UMR 5805 (CNRS/UB1), 2 rue Jolyet, F-33120, Arcachon, France. \\ ${ }^{5}$ Instituto Español de Oceanografía, Punta del Apio, Aptdo. 1552, E-36200 Vigo, Spain. E-mail: ana.ramos@vi.ieo.es
}

SUMMARY: During the austral summers of 2003 and 2006 suprabenthic assemblages were investigated at 35 stations located in the Bellingshausen Sea and off the western Antarctic Peninsula, at depths ranging from 45 to $3280 \mathrm{~m}$. Suprabenthos was collected with a Macer-GIROQ sledge equipped with an automatic opening and closing system. This study presents data on the occurrence and relative abundance of the major suprabenthic taxa collected in the water layer immediately adjacent to the bottom (10-140 $\mathrm{cm}$ above bottom). Assemblages were dominated by Peracarida and the most common groups were Amphipoda, Mysida, Isopoda and Cumacea. Among the 66 taxa identified, 40 account for more than $80 \%$ of the dissimilarity levels among any of the different combinations between groups of stations. The highest dissimilarity values in the segregation of the pairwise station groups were obtained for Mysidae, Lysianassidae, Gammaridea, Cumacea and Munnopsidae. The recorded faunistic patterns showed dependences in the environmental variables depth and percentage of mud in the sediment, as single and combined variables.

Keywords: suprabenthos, Bellingshausen Sea, Antarctic Peninsula, Southern Ocean.

RESUMEN: FAuna suprabentónica del mar de Bellingshausen y del oeste de la Península AntáRtica: distriBUCIÓN ESPACIAL Y ESTRUCTURA DE LAS COMUNIDADES. - Durante los veranos australes 2003 y 2006 , se investigaron las comunidades suprabentónicas en un total de 35 estaciones localizadas en el mar de Bellingshausen y al oeste de la Península Antártica, en profundidades de 45-3280 m. El suprabentos se muestreó con un trineo tipo Macer-GIROQ equipado con un sistema de abertura-cierre. Este estudio presenta los datos relativos a la abundancia de los principales taxones suprabentónicos recolectados en la capa de agua inmediatamente adyacente al fondo $(10-140 \mathrm{~cm})$. Las comunidades estaban dominadas por los peracáridos y los grupos más abundantes fueron Amphipoda, Mysida, Isopoda y Cumacea. De entre los 66 taxones identificados, 40 explican más del $80 \%$ de los niveles de disimilaridad entre cualesquiera de las diversas combinaciones entre grupos de estaciones. Los valores más altos de disimilaridad en la segregación de las parejas de grupos de estaciones fueron obtenidos por Mysidae, Lysianassidae, Gammaridea, Cumacea y Munnopsidae. La mejor combinación de variables ambientales con los datos faunísticos registrados es una combinación de la profundidad y del porcentaje del fango en el sedimento. En particular, la profundidad es la variable que muestra el mejor resultado cuando cada variable abiótica se considera por separado.

Palabras clave: suprabentos, mar de Bellingshausen, Península Antártica, Antártida. 


\section{INTRODUCTION}

Suprabenthic organisms are known to live in the benthic boundary layer and to play an important role in bentho-pelagic food webs (Mauchline, 1980; Brandt, 1995). They are highly consumed by a great diversity of predators such as seals, penguins, demersal fish and shrimps, and contribute to the recycling of particulate organic matter to higher trophic levels of the marine ecosystem (Brandt, 1993, 1995; Svavarsson et al., 1993). The contribution of suprabenthos to ecosystem functioning has also been demonstrated for Antarctic waters and is therefore taken into consideration in bentho-pelagic coupling, a new developing area in modern Antarctic research (Arntz et al., 2005).

Investigations on Antarctic suprabenthic assemblages are still rare. They have been done using different types of sledges and dredges, and the geographical coverage of the whole Southern Ocean remains only very partially fulfilled (San Vicente et al., 1997, 2007: South Shetland Islands and Bransfield Strait; Linse et al., 2002; Lörz and Brandt, 2003; Weddell Sea and Northwest Antarctic Peninsula; Rehm et al., 2007; Ross Sea; Brökeland et al., 2007 and Brandt et al., 2007a,b: deep Weddell Sea and adjacent areas; South Sandwich arc: Kaiser et al., 2008). Thus, the Antarctic sector corresponding to the Bellingshausen Sea and western Antarctic Peninsula have remained virtually unknown until nowadays.
As an integrated study of benthic ecosystems, the BENTART research programme was a good opportunity to fill this gap and bring new insights on poorly known Antarctic suprabenthic assemblages (Ramos, 2003). The BENTART 03 cruise (24 January to 3 March, 2003) and the BENTART 06 cruise (2 January to 17 February, 2006) were carried out on board the RV Hesperides in the Bellingshausen Sea and off the southwestern Antarctic Peninsula. The main objectives of the present study were to provide new data on the occurrence and geographical and bathymetrical distribution of their suprabenthic assemblages.

\section{MATERIALS AND METHODS}

\section{Field sampling}

During the BENTART-03 and BENTART-06 cruises (2003 and 2006 austral summers, respectively), 35 stations (depth range: $45-3280 \mathrm{~m}$ ) located in the Bellingshausen Sea (from the Antarctic Peninsula to Thurston Island) and off the western Antarctic Peninsula (from Gerlache Strait to Marguerite Bay) were sampled in order to study their benthic communities (Fig. 1, Table 1).

Suprabenthic samples were collected with a modified Macer-GIROQ sledge (Cartes et al., 1994). This sledge is equipped with 3 superimposed nets $(0.5 \mathrm{~mm}$

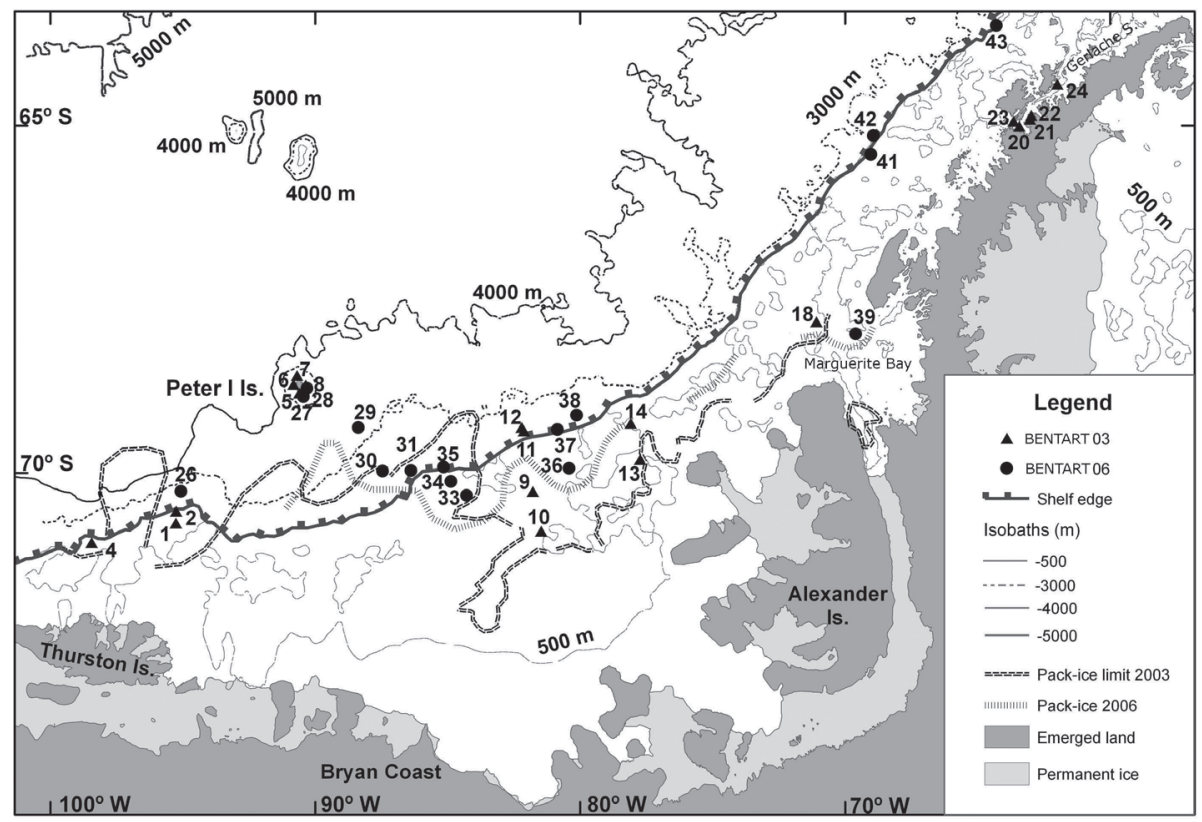

FIg. 1. - Position of the BENTART-03 and BENTART-06 sampling stations in the Bellingshausen Sea and off the western Antarctic Peninsula. 


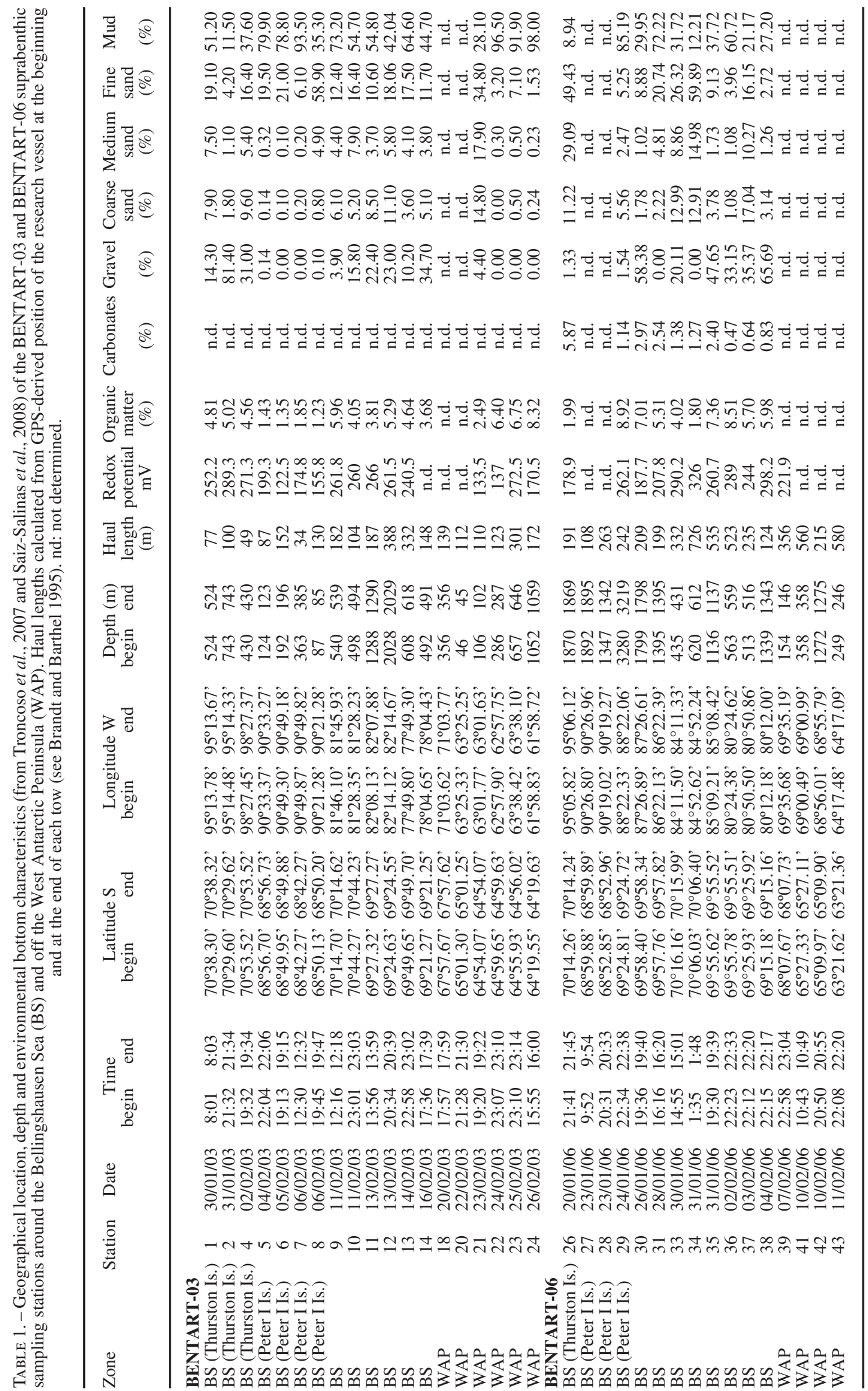


mesh size) that simultaneously sample the motile fauna in the $10-50 \mathrm{~cm}\left(\mathrm{~N}_{1}\right), 55-95 \mathrm{~cm}\left(\mathrm{~N}_{2}\right)$ and $100-140$ $\mathrm{cm}\left(\mathrm{N}_{3}\right)$ near-bottom water layers. Each net is fixed to an anterior rectangular box (width $80 \mathrm{~cm}$; height $40 \mathrm{~cm}$ ) and equipped with an opening-closing system activated by contact with the sea floor (to prevent contamination of suprabenthic samples by organisms from the water column).

The sledge was towed over the sea bottom for 2-12 minutes at 1.5-2 knots. Sledge haul length was estimated from GPS-derived position of the research vessel at the beginning and at the end of each tow by means of the following formula (Brandt and Barthel, 1995; Linse et al., 2002; Lörz and Brandt, 2003):

Haul length $(m)=1852 \sqrt{ }\left(\left(\Delta \text { lat }^{\prime}\right)^{2}+\cos \text { lat' }^{\prime} \Delta \text { long' }^{\prime}\right)^{2}$

where $\Delta$ lat' and $\Delta$ long' are the difference in latitude and longitude between starting and ending points, respectively. Distance trawled was determined using the remote acoustic SCANMAR HC4 trawl system attached to the sledge which can monitor in real time the bottom contact of the sledge at station depths $<1200 \mathrm{~m}$. At deeper stations $(>1200$ $\mathrm{m})$, the sledge was lowered at $1 \mathrm{~m} / \mathrm{sec}$ until the cable length to water depth ratio reached 1.0 , then $0.5 \mathrm{~m} / \mathrm{sec}$ was applied until the sledge contacted bottom at a mean cable length to water depth ratio of 1.5 (as indicated by the winch tension meter). Total distances across the seafloor varied from 34 to $726 \mathrm{~m}$. Thus, depending on the sampled depth, the calculation of the trawl distances was considered as accurate in shallow water samples $(<1200 \mathrm{~m})$ and was approximately exact enough for the deeper samples (Brenke, 2005). Density values were calculated from areas swept by the sledge on the bottom (haul length $\mathrm{x}$ net box width) and standardised to individuals $/ 100 \mathrm{~m}^{2}$. In total, $8193 \mathrm{~m}^{2}$ of ocean bottom were sampled with the suprabenthic sledge. It must be reported that the erratic presence of large drop stones over the sea floor (resulting from iceberg rafting) greatly perturbed sledge samplings, particularly at stations 11, 12, 28 and 29 in the Bellingshausen Sea.

The material collected from the 35 sampling stations was sorted on board to family level, where possible, for the 9 major taxonomic groups (pycnogonids, leptostracans, mysids, amphipods, cumaceans, isopods, tanaidaceans, euphausiids and decapods), and then preserved with $10 \%$ neutral formalin before laboratory examination for further accurate identifi- cations. Small zooplankton components (copepods, ostracods, chaetognaths) and demersal fishes were excluded from this study.

Environmental characteristics (Table 1) related to surface sediments (redox potential, organic content, carbonates and granulometric composition) were taken from Troncoso et al. (2007) and Saiz-Salinas et al. (2008).

\section{Data analysis}

Data were organised at each station by taxa matrices constructed with the family level for almost all the major taxonomic groups (66 families and 9 orders). Univariate measurements such as total abundance $\left(\mathrm{N}_{1}, \mathrm{~N}_{2}, \mathrm{~N}_{3}\right.$ and $\left.\mathrm{N}_{\mathrm{t}}\right)$, number of $\operatorname{taxa}(\mathrm{T})$, the Shannon-Wiener diversity index $\left(\mathrm{H}^{\prime}\right.$, $\log _{\mathrm{e}}$ ) and Pielou's evenness (J') were calculated for each sampling station. The composition of suprabenthic assemblages was analysed by means of non-parametric multivariate techniques as described by Field et al. (1982) using the PRIMER v 5.0 (Plymouth Routines in Multivariate Ecological Research) software package (Clarke and Gorley, 2001). A matrix of similarity between samples was constructed by means of the Bray-Curtis coefficient applied to fourth-root transformed abundances $\left(\mathrm{N}_{\mathrm{t}}\right.$, ind./ $100 \mathrm{~m}^{2}$ ) to down-weight the contribution of the most abundant taxa. From this matrix the 35 suprabenthic samples were classified by cluster analysis based on the complete linkage sorting algorithm. An ordination analysis was performed by means of non-metric multidimensional scaling. The SIMPER routine was then used to identify taxa that mostly contributed to distinctions between station groups.

The BIO-ENV procedure of the PRIMER package was used to characterise the possible relationship between suprabenthic distributions in the study area and the measured environmental variables. Specifically, depth (m) and the following abiotic variables were considered in the analyses: redox potential (Eh) of sediments, organic matter content $(\%)$ and all granulometric fractions (\%; gravel: $>2 \mathrm{~mm}$, coarse sand: $>0.5 \mathrm{~mm}$, medium sand: $>0.25 \mathrm{~mm}$, fine sand: $>0.0625 \mathrm{~mm}$, mud: $<0.0625 \mathrm{~mm}$ ). Carbonates as well as stations 18, 20 (from BENTART-03), 27, 28, 39, 41, 42 and 43 (from BENTART-06) were discarded from the analysis due to the lack of such sediment data. All variables were previously transformed by $\log (\mathrm{x}+1)$. 


\section{RESULTS}

\section{Abundance, near-bottom vertical distribution, taxa richness and diversity}

The overall material collected in the $10-140 \mathrm{~cm}$ water layer of the 35 sampling stations contained a total of 12613 individuals sorted into 9 major zoological groups (amphipods: 50.4\% of total individuals; mysids: 28.6\%; isopods: $12.4 \%$; cumaceans: 4.4\%; pycnogonids: $1.5 \%$; euphausiids: $1.3 \%$; tanaids: $0.9 \%$; decapods: $0.5 \%$; leptostracans: $0.1 \%$ ) and 66 taxa (amphipods: 24 taxa; isopods: 21; cumaceans: 6; pycnogonids: 5; decapods: 4; mysids: 3; euphausiids: 1 ; tanaids: 1 and leptostracans: 1 ) (Table 2).

In most major taxonomic groups, the fauna showed a clear vertical distribution gradient with a decrease in abundance between the $10-50 \mathrm{~cm}$, the $55-95 \mathrm{~cm}$ and the $100-140 \mathrm{~cm}$ water layers above the
TABLE 2. - Total abundance (number of individuals) and total taxon richness $\left(\mathrm{T}_{\mathrm{Nt}}\right.$, total number of families) of the major suprabenthic groups in the $10-50 \mathrm{~cm}\left(\mathrm{~N}_{1}\right), 55-95 \mathrm{~cm}\left(\mathrm{~N}_{2}\right), 100-140 \mathrm{~cm}\left(\mathrm{~N}_{3}\right)$ and combined 10-140 cm $\left(\mathrm{N}_{\mathrm{t}}\right)$ near-bottom water layers sampled.

\begin{tabular}{|c|c|c|c|c|c|}
\hline Taxonomic group & $\mathrm{N}_{1}$ & $\mathrm{~N}_{2}$ & $\mathrm{~N}_{3}$ & $\mathrm{~N}_{\mathrm{t}}$ & $\mathrm{T}_{\mathrm{Nt}}$ \\
\hline Pycnogonida & 154 & 29 & 6 & 189 & 5 \\
\hline Leptostraca & 7 & 1 & 0 & 8 & 1 \\
\hline Mysida and Lophogastrida & 2632 & 754 & 217 & 3603 & 3 \\
\hline Amphipoda & 5416 & 617 & 325 & 6358 & 24 \\
\hline Cumacea & 511 & 29 & 11 & 551 & 6 \\
\hline Isopoda & 1433 & 111 & 19 & 1563 & 21 \\
\hline Tanaidacea & 98 & 12 & 1 & 111 & 1 \\
\hline Euphausiacea & 49 & 85 & 35 & 169 & 1 \\
\hline Decapoda & 50 & 7 & 4 & 61 & 4 \\
\hline Total BENTART 03-06 & 10350 & 1645 & 618 & 12613 & 66 \\
\hline
\end{tabular}

bottom $(82.1 \%, 13.0 \%$ and $4.9 \%$ of total abundance, respectively). Only the euphausiids were less abundant in the lowermost sampling level (Table 2).

Considering the whole $10-140 \mathrm{~cm}$ water layer by combining the abundances of the three nets

TABLE 3. - Abundance (ind./100 $\mathrm{m}^{2}$ ) of the major taxonomical groups, taxa richness (T), Shannon-Wiener diversity (H', log ${ }_{\mathrm{e}}$ ) and Pielou evenness index (J') of the suprabenthic fauna sampled in the 10-140 cm near-bottom water layer. PYC, Pycnogonida; LEP, Leptostraca, MYS,

Mysida and Lophogastrida; AMP, Amphipoda; CUM, Cumacea; ISO, Isopoda; TAN, Tanaidacea; EUP, Euphausiacea; DEC, Decapoda.

\begin{tabular}{|c|c|c|c|c|c|c|c|c|c|c|c|c|c|}
\hline Zone/Station & PYC & LEP & MYS & AMP & CUM & ISO & TAN & EUP & DEC & ind. $/ 100 \mathrm{~m}^{2}$ & $\mathrm{~T}$ & $\mathrm{H}^{\prime}$ & J' \\
\hline \multicolumn{14}{|l|}{ Bellingshausen Sea } \\
\hline 1 & 2 & 2 & 58 & 138 & 8 & 76 & 6 & 2 & 5 & 297 & 15 & 1.71 & 0.63 \\
\hline 2 & 3 & 0 & 10 & 18 & 4 & 9 & 1 & 1 & 1 & 47 & 13 & 2.26 & 0.88 \\
\hline 4 & 0 & 0 & 10 & 15 & 0 & 3 & 0 & 0 & 3 & 31 & 6 & 1.63 & 0.91 \\
\hline 5 & 7 & 0 & 3 & 513 & 4 & 27 & 3 & 0 & 1 & 558 & 9 & 0.44 & 0.20 \\
\hline 6 & 3 & 0 & 62 & 35 & 3 & 14 & 3 & 3 & 0 & 123 & 11 & 1.44 & 0.60 \\
\hline 7 & 4 & 0 & 7 & 805 & 70 & 48 & 4 & 0 & 0 & 938 & 9 & 1.11 & 0.51 \\
\hline 8 & 4 & 0 & 1 & 470 & 17 & 75 & 32 & 1 & 0 & 600 & 15 & 1.00 & 0.37 \\
\hline 9 & 1 & 0 & 10 & 47 & 1 & 5 & 0 & 1 & 0 & 65 & 9 & 1.07 & 0.49 \\
\hline 10 & 0 & 0 & 49 & 32 & 1 & 4 & 1 & 0 & 1 & 88 & 10 & 1.17 & 0.51 \\
\hline 11 & 0 & 0 & 1 & 8 & 0 & 1 & 0 & 1 & 0 & 11 & 4 & 0.92 & 0.66 \\
\hline 12 & 0 & 0 & 0 & 1 & 0 & 0 & 0 & 1 & 0 & 2 & 2 & 0.68 & 1.00 \\
\hline 13 & 0 & 0 & 24 & 64 & 7 & 11 & 2 & 0 & 0 & 108 & 12 & 1.33 & 0.53 \\
\hline 14 & 1 & 0 & 5 & 25 & 4 & 7 & 0 & 0 & 0 & 42 & 8 & 1.36 & 0.66 \\
\hline 26 & 1 & 0 & 10 & 139 & 6 & 24 & 0 & 5 & 4 & 189 & 30 & 2.37 & 0.70 \\
\hline 27 & 1 & 0 & 218 & 127 & 0 & 69 & 2 & 7 & 0 & 424 & 15 & 1.63 & 0.60 \\
\hline 28 & 0 & 0 & 1 & 1 & 0 & 2 & 0 & 6 & 0 & 10 & 7 & 1.42 & 0.73 \\
\hline 29 & 1 & 0 & 1 & 4 & 0 & 3 & 1 & 6 & 0 & 16 & 14 & 2.17 & 0.82 \\
\hline 30 & 1 & 1 & 22 & 121 & 56 & 114 & 0 & 1 & 1 & 317 & 33 & 3.08 & 0.88 \\
\hline 31 & 3 & 2 & 28 & 161 & 35 & 84 & 1 & 0 & 0 & 314 & 28 & 2.80 & 0.84 \\
\hline 33 & 2 & 0 & 18 & 40 & 7 & 3 & 0 & 0 & 0 & 70 & 22 & 2.29 & 0.74 \\
\hline 34 & 7 & 0 & 40 & 377 & 24 & 92 & 5 & 0 & 0 & 545 & 37 & 2.45 & 0.68 \\
\hline 35 & 1 & 0 & 3 & 20 & 5 & 9 & 0 & 2 & 0 & 40 & 27 & 2.94 & 0.89 \\
\hline 36 & 0 & 0 & 16 & 19 & 2 & 7 & 2 & 1 & 0 & 47 & 24 & 2.55 & 0.80 \\
\hline 37 & 1 & 0 & 27 & 33 & 2 & 7 & 0 & 5 & 0 & 75 & 20 & 2.14 & 0.72 \\
\hline 38 & 0 & 2 & 39 & 90 & 15 & 37 & 7 & 1 & 2 & 193 & 32 & 2.90 & 0.84 \\
\hline \multicolumn{14}{|l|}{ Antarctic Peninsula } \\
\hline 18 & 0 & 0 & 0 & 6 & 2 & 1 & 0 & 0 & 0 & 9 & 3 & 0.80 & 0.73 \\
\hline 20 & 0 & 0 & 15 & 26 & 0 & 1 & 0 & 0 & 2 & 44 & 4 & 0.92 & 0.67 \\
\hline 21 & 0 & 0 & 0 & 11 & 0 & 0 & 0 & 0 & 0 & 11 & 1 & & \\
\hline 22 & 1 & 0 & 1234 & 12 & 0 & 0 & 0 & 1 & 43 & 1291 & 6 & 0.22 & 0.12 \\
\hline 23 & 0 & 0 & 8 & 10 & 0 & 0 & 0 & 10 & 0 & 28 & 6 & 1.27 & 0.71 \\
\hline 24 & 0 & 0 & 31 & 26 & 13 & 8 & 6 & 20 & 0 & 104 & 9 & 1.76 & 0.80 \\
\hline 39 & 1 & 0 & 1 & 16 & 5 & 6 & 0 & 4 & 0 & 33 & 22 & 2.56 & 0.83 \\
\hline 41 & 1 & 0 & 8 & 27 & 6 & 7 & 0 & 2 & 0 & 51 & 29 & 2.79 & 0.83 \\
\hline 42 & 57 & 0 & 6 & 194 & 12 & 13 & 0 & 1 & 0 & 283 & 34 & 1.68 & 0.48 \\
\hline 43 & 1 & 0 & 275 & 177 & 4 & 33 & 0 & 3 & 0 & 493 & 37 & 1.93 & 0.53 \\
\hline
\end{tabular}




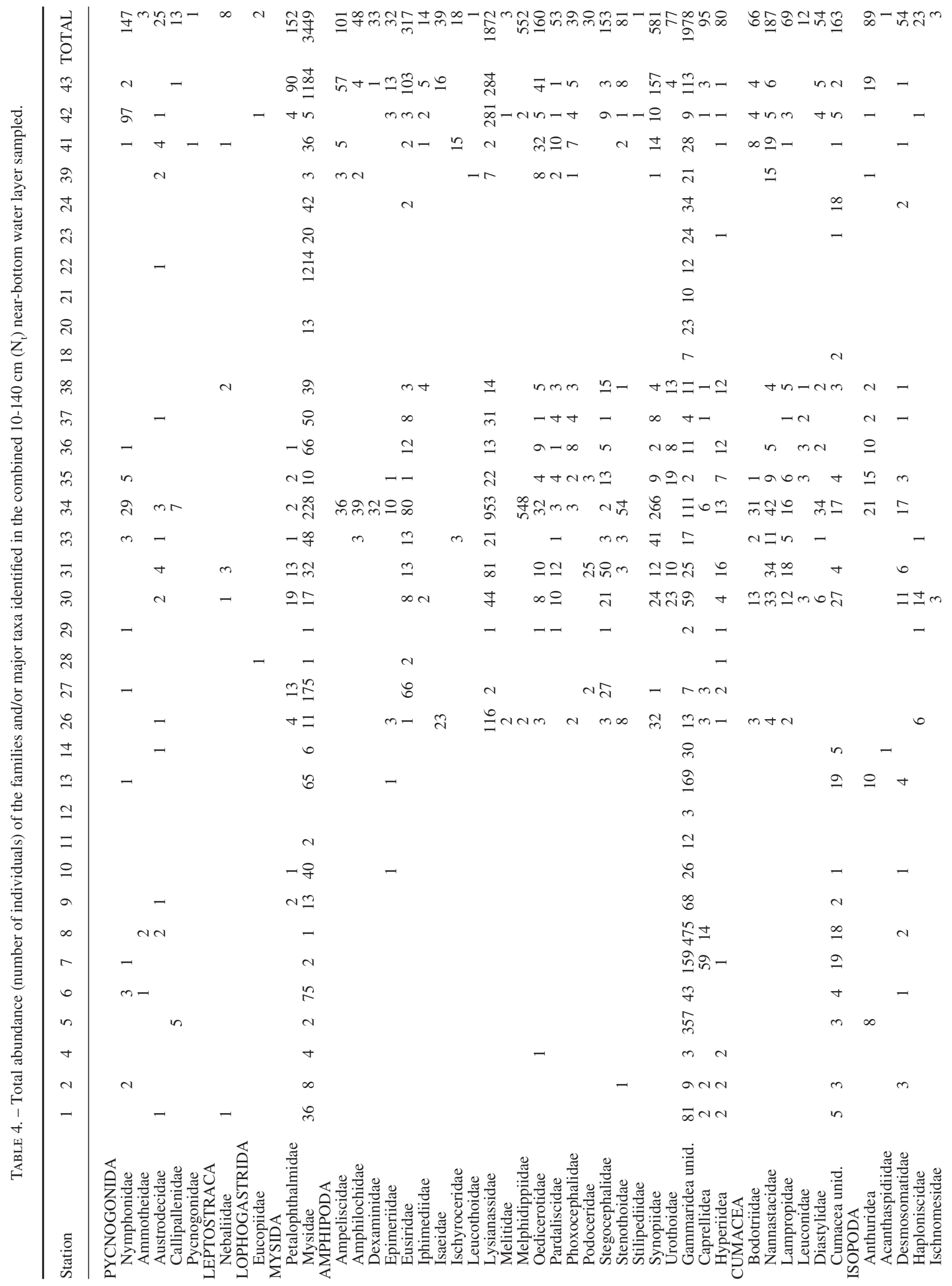




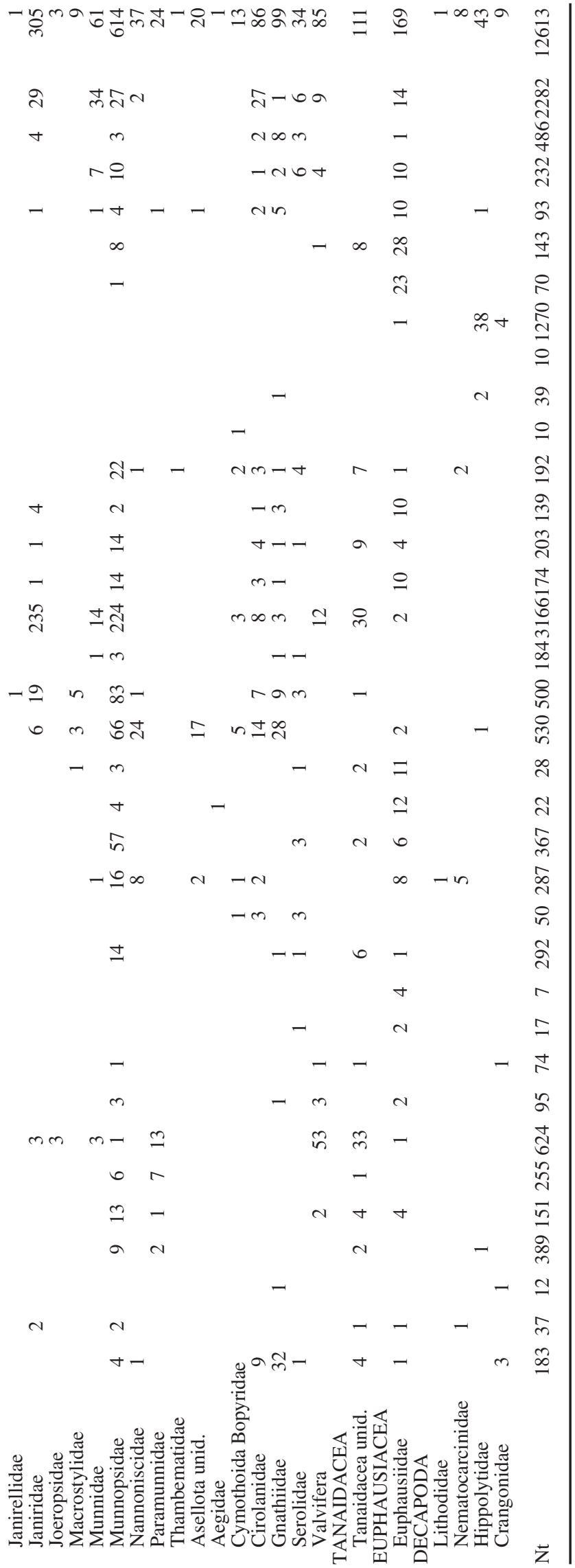

sampled by the sledge, the lowest abundance value was recorded at station $12\left(2 \mathrm{ind} . / 100 \mathrm{~m}^{2}\right)$ at 2029 $m$ depth in the central part of the Bellingshausen Sea, whereas the highest was recorded at station 22 (1291 ind/100 $\mathrm{m}^{2}$ ) at $287 \mathrm{~m}$ depth in the Gerlache Strait, Antarctic Peninsula. The high number of mysids was the reason for the high abundance at station 22 (Table 3 ).

At the family level adopted in this study, taxon richness ranged from 1 (station 21, Antarctic Peninsula) to 37 families (station 34, Bellingshausen Sea; station 43, Antarctic Peninsula) (Table 4). The six most abundant taxa were Mysidae, Lysianassidae, Melphidippiidae, Synopiidae, Gammaridea unid. and Munnopsidae $(76.7 \%$ of the collected material). According to their occurrence at the 35 sampling stations, the most frequent groups were amphipods (35 stations), mysids (32), isopods (32), cumaceans (25), euphausiids (23) and pycnogonids (22). The highest Shannon-Wiener diversity value was recorded at station 30 in the Bellingshausen Sea $\left(H^{\prime}=3.08\right)$, whereas the lowest was found at station 21 of the Antarctic Peninsula $\left(\mathrm{H}^{\prime}=0.00\right)$. Evenness ranged from 1.00 (station 12) to 0.12 (station 22) (Table 3).

\section{Suprabenthic assemblages}

Based on taxa abundances in the $10-140 \mathrm{~cm}$ nearbottom water layer, five main groups (A, B, C, D and E) were discriminated by the cluster analysis of the 35 sampling stations, with a similarity level of about $30 \%$ (Fig. 2). All groups were significantly different (ANOSIM Global $\mathrm{R}=0.926, P<0.1$, all pairwise $P<0.5)$ in terms of community structure. The MDS ordination plot (Fig. 3) shows similar results to those

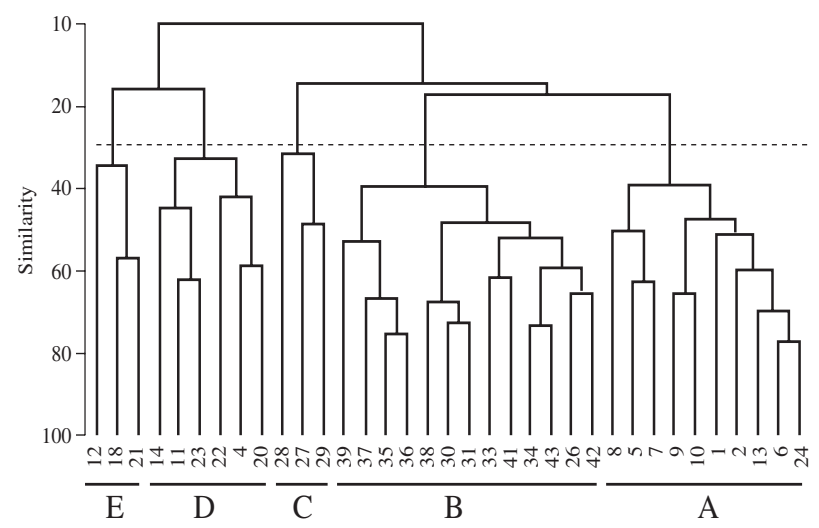

FIG. 2. - Hierarchical cluster analysis (square root-transformed abundances, Bray-Curtis similarity coefficient) of the 35 sampling 


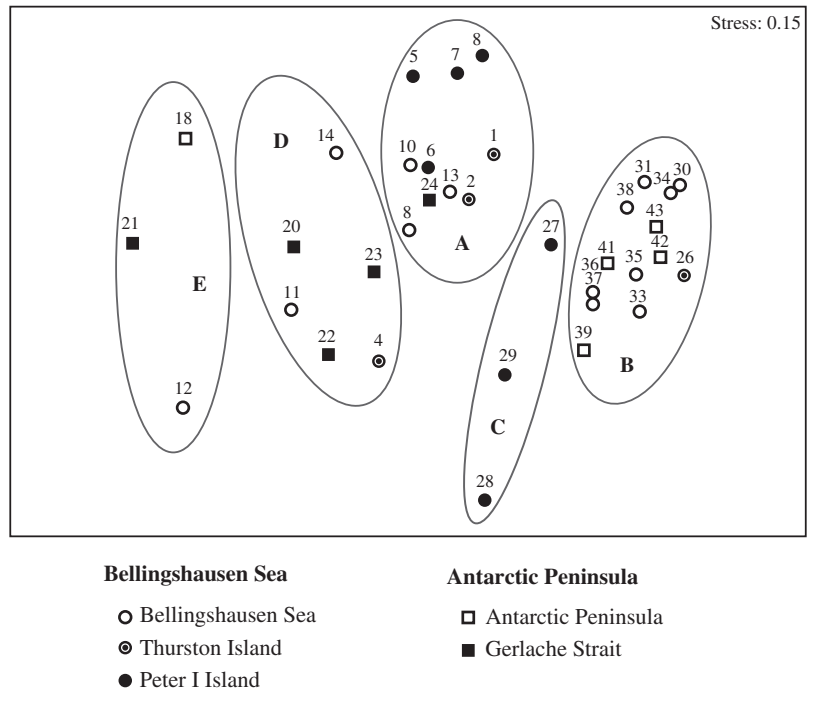

FIG. 3. - Non-metric multidimensional scaling (MDS) ordination plot of adjusted Bray-Curtis similarities between BENTART-03 and BENTART-06 samples.

of the dendogram, with an acceptable stress value (0.15). Sampling sites are segregated along the first dimension, which cannot be easily identified as an environmental and/or geographical gradient but can be identified as a biodiversity (number of taxa) gradient.

The results of the SIMPER analysis on groups $\mathrm{A}, \mathrm{B}, \mathrm{C}, \mathrm{D}$ and $\mathrm{E}$ are shown in Table 5. Average within-group similarities ranged from $41.02 \%$ for group C to $56.37 \%$ for group B. Group A includes 9 stations from the Bellingshausen Sea (85-743 m depth, Antarctic continental shelf) and 1 station from the Antarctic Peninsula (1052-1059 m depth) with a moderate taxa richness (9-15 taxa) and dominated by Amphipoda (Gammaridea), Mysidae, Cumacea and Isopoda (Munnopsidae); these taxa account for $71.09 \%$ of the average within-group similarity.

Group B includes 9 stations from the Bellingshausen Sea (431-1870 m depth) and 4 stations from the Antarctic Peninsula (146-1275 m depth) with the highest taxa richness (20-37 taxa) of all the studied assemblages; 9 taxa account for $53.23 \%$ of the average within-group similarity (decreasing order): Lysianassidae, Mysidae, Gammaridea, Synopiidae, Munnopsidae, Nannastacidae, Oedicerotidae, Eusiridae and Cirolanidae.

Group C includes 3 stations located off Peter I Island (1342-3219 $\mathrm{m}$ depth) characterised by a moderate taxa richness (7-15 taxa) and dominated by Euphausiidae, Munnopsidae, Hyperiidea and Mysidae (account for $73.37 \%$ of the average within-group similarity).
TABLE 5. - Results of SIMPER analysis. Average similarity within groups. Families are ranked according to their average contribution to similarity within the five stations groups A-E discriminated by the multivariate analysis of the 35 sampling stations. A cut-off at a cumulative similarity of $80 \%$ was applied to the data analysis. Unid: unidentified; Av.Ab.: average abundance; Av.Sim.: average similarity; Sim./SD: ratio similarity/standard deviation; Contr.(\%): percentage contribution to total similarity; Cum.(\%): percentage of cumulative similarity.

\begin{tabular}{|c|c|c|c|c|c|}
\hline & Av.Ab. & Av.Sim. & $\begin{array}{l}\text { Sim./ } \\
\text { SD }\end{array}$ & $\begin{array}{c}\text { Contr. } \\
(\%)\end{array}$ & Cum. \\
\hline \multicolumn{6}{|c|}{ Group A (av. sim.: $54.60 \%$ ) } \\
\hline Gammaridea unid. & 189.86 & 14.30 & 4.32 & 26.18 & 26.18 \\
\hline Mysidae & 25.33 & 9.63 & 2.66 & 17.65 & 43.83 \\
\hline Cumacea indet. & 12.94 & 7.58 & 6.33 & 13.87 & 57.70 \\
\hline Munnopsidae & 7.00 & 7.31 & 4.09 & 13.39 & 71.09 \\
\hline Tanaidacea unid. & 5.86 & 5.32 & 1.89 & 9.74 & 80.84 \\
\hline \multicolumn{6}{|c|}{ Group B (av. sim.: $56.37 \%$ ) } \\
\hline Lysianassidae & 45.49 & 4.44 & 3.54 & 7.88 & 7.88 \\
\hline Mysidae & 34.31 & 4.40 & 3.45 & 7.81 & 15.69 \\
\hline Gammaridea unid. & 11.12 & 3.90 & 4.28 & 6.93 & 22.61 \\
\hline Synopiidae & 12.16 & 3.52 & 3.87 & 6.25 & 28.86 \\
\hline Munnopsidae & 14.06 & 3.51 & 5.15 & 6.23 & 35.09 \\
\hline Nannastacidae & 5.86 & 2.90 & 1.99 & 5.14 & 40.22 \\
\hline Oedicerotidae & 3.76 & 2.71 & 2.09 & 4.80 & 45.03 \\
\hline Eusiridae & & 2.48 & 1.85 & 4.40 & 49.92 \\
\hline Cirolanidae & 2.20 & 2.15 & 2.10 & 3.81 & 53.23 \\
\hline Pardaliscidae & 1.88 & 2.08 & 1. & 3.70 & 56.93 \\
\hline Euph & 1.98 & 2.04 & 1.28 & 3.62 & 60.55 \\
\hline Gnathiidae & 2.57 & 1.99 & 1.87 & 3.53 & 64.08 \\
\hline Stego & 5.6 & 1.93 & 1. & 3.4 & 67.51 \\
\hline phalidae & 1.13 & 1.58 & 1.08 & 2.80 & 70.30 \\
\hline Lam & 2.57 & 1.54 & 1.11 & 2.73 & 73.04 \\
\hline Нуре & 2.54 & 1.32 & 1.05 & 2.35 & 75.38 \\
\hline Janiridae & 5.19 & 1.18 & 0.88 & 2.09 & 77.47 \\
\hline Austrodecidae & 061 & 1.11 & 088 & 1.97 & 79.44 \\
\hline Petalophthalmidae & 3.48 & 1.07 & 0.81 & 1.90 & 81.35 \\
\hline \multicolumn{6}{|c|}{ Group C (av. sim.: 41.02\%) } \\
\hline Euphausiidae & 6.11 & 10.70 & 2.6 & 26.08 & 26.08 \\
\hline Munnopsidae & 23.14 & 7.84 & 2.74 & 19.12 & 45.19 \\
\hline Hyperiidea & 1.10 & & 2.69 & 14.09 & 59.28 \\
\hline Mysidae & 67.85 & 5.78 & 2.69 & 14.09 & 73.37 \\
\hline Eusiridae & 25.78 & 1.94 & 0.58 & 4.72 & 78.09 \\
\hline Tanaidacea unid. & 1.12 & 1.68 & 0.58 & 4.08 & 82.18 \\
\hline \multicolumn{6}{|c|}{ Group D (av. sim.: 46.04\%) } \\
\hline Gammaridea unid. & 14.81 & 21.20 & 4.5 & 46.05 & 46.05 \\
\hline Mysidae & 212.19 & 17.3 & 4.82 & 37.61 & 83.66 \\
\hline \multicolumn{6}{|c|}{ Group E (av. sim.: 47.45\%) } \\
\hline Gammaridea unid. & 6.21 & 47.45 & 4.04 & 100.00 & 100.00 \\
\hline
\end{tabular}

Group D includes 3 stations from the Antarctic Peninsula (45-657 $\mathrm{m}$ depth) and 3 from the Bellingshausen Sea (430-1290 m depth). The corresponding assemblage is characterised by a low taxa richness (4-8 taxa) and the main taxa in terms of major contribution to the average within-group similarity are Gammaridea and Mysidae (83.66\%).

Group E includes 2 stations from the Antarctic Peninsula (102-356 m depth) and one from the Bellingshausen Sea (2028-2029 m depth) with the lowest taxa richness (1-3 taxa) of all the studied assemblages; in this group the Gammaridea account for $100 \%$ of the average within-group similarity.

Among the 66 suprabenthic taxa considered in this study, 40 account for roughly $80 \%$ of the 
TABLE 6. - Results of SIMPER analysis. Average dissimilarities between station groups pairwise discriminated by the multivariate analysis of the 35 sampling stations and contribution (\%) of each taxon to total dissimilarity within each pair. A cut-off at a cumulative dissimilarity of $80 \%$ was applied to the data analysis.

\begin{tabular}{|c|c|c|c|c|c|c|c|c|c|c|}
\hline Station group pairwises & $\mathrm{AB}$ & $\mathrm{AC}$ & $\mathrm{AD}$ & $\mathrm{AE}$ & $\mathrm{BC}$ & $\mathrm{BD}$ & $\mathrm{BE}$ & $\mathrm{CD}$ & $\mathrm{CE}$ & $\mathrm{DE}$ \\
\hline Average dissimilarites & 68.15 & 66.52 & 62.69 & 78.77 & 65.36 & 76.27 & 89.91 & 71.97 & 87.54 & 66.15 \\
\hline \multicolumn{11}{|l|}{ PYCNOGONIDA } \\
\hline Nymphonidae & 1.96 & 2.83 & 2.85 & 2.93 & 1.99 & 1.91 & 1.89 & 3.19 & 3.40 & \\
\hline Austrodecidae & 1.65 & & 2.62 & & 2.01 & 1.72 & 1.96 & & & \\
\hline \multicolumn{11}{|l|}{ LOPHOGASTRIDA } \\
\hline Eucopiidae & & 1.72 & & & & & & & 3.33 & \\
\hline \multicolumn{11}{|l|}{ MYSIDA } \\
\hline Petalophthalmidae & 2.08 & 2.91 & & & 2.72 & 2.29 & 2.23 & 2.58 & & \\
\hline Mysidae & 2.03 & 6.45 & 6.85 & 13.38 & 4.03 & 3.38 & 5.85 & 9.61 & 10.27 & 29.64 \\
\hline \multicolumn{11}{|l|}{ AMPHIPODA } \\
\hline Eusiridae & 3.12 & 5.25 & & & 3.32 & 3.60 & 3.55 & 6.89 & 7.78 & \\
\hline Lysianassidae & 5.74 & 2.79 & & & 4.51 & 6.20 & 6.10 & 3.45 & 3.66 & \\
\hline Oedicerotidae & 3.36 & & & & 2.99 & 3.20 & 3.59 & 2.57 & & \\
\hline Pardaliscidae & 2.72 & & & & 2.31 & 2.97 & 2.95 & & & \\
\hline Phoxocephalidae & 2.32 & & & & 2.59 & 2.54 & 2.54 & & & \\
\hline Podoceridae & & & & & 1.39 & & & & & \\
\hline Stegocephalidae & 2.98 & 4.06 & & & 2.92 & 3.21 & 3.15 & 4.93 & 5.12 & \\
\hline Stenothoidae & 1.77 & & & & 1.96 & 1.90 & 1.84 & & & \\
\hline Synopiidae & 4.36 & & & & 4.06 & 4.72 & 4.66 & & & \\
\hline Urothoidae & 1.77 & & & & 1.95 & 1.89 & 1.85 & & & \\
\hline Gammaridea unid. & 4.33 & 11.49 & 7.57 & 10.39 & 2.93 & 1.39 & 1.35 & 8.07 & 7.45 & 7.07 \\
\hline Caprellidea & 2.43 & 3.91 & 4.34 & 4.29 & 1.69 & & & & & \\
\hline Hyperiidea & 2.14 & 3.81 & 3.40 & 2.15 & 1.67 & 2.30 & 2.38 & 4.73 & 6.99 & 5.37 \\
\hline \multicolumn{11}{|l|}{ CUMACEA } \\
\hline Bodotriidae & 1.83 & & & & 2.02 & 1.95 & 1.91 & & & \\
\hline Nannastacidae & 3.64 & & & & 4.04 & 3.94 & 3.90 & & & \\
\hline Lampropidae & 2.47 & & & & 2.73 & 2.66 & 2.61 & & & \\
\hline Leuconidae & & & & & & 1.23 & & & & \\
\hline Diastylidae & 1.51 & & & & 1.66 & 1.69 & 1.56 & & & \\
\hline Cumacea unid. & 2.99 & 7.75 & 7.93 & 8.01 & 1.95 & 1.99 & 1.92 & & 2.72 & 7.20 \\
\hline \multicolumn{11}{|l|}{ ISOPODA } \\
\hline Anthuridea & 2.11 & 1.62 & & 2.19 & 2.23 & 2.19 & 2.18 & & & \\
\hline Desmosomatidae & 1.22 & 3.33 & 4.30 & 4.49 & 1.80 & 1.74 & 1.70 & & & \\
\hline Haploniscidae & & & & & 1.42 & & & & & \\
\hline Janiridae & 2.27 & & & & 2.60 & 2.52 & 2.48 & & & \\
\hline Munnidae & & & & & 1.49 & 1.46 & 1.45 & & & \\
\hline Munnopsidae & 1.49 & 2.98 & 8.47 & 9.69 & 2.09 & 4.26 & 5.44 & 8.83 & 11.11 & \\
\hline Paramunnidae & 1.73 & 2.77 & 3.51 & 3.52 & & & & & & \\
\hline Aegidae & & 1.72 & & & & & & 2.54 & 3.33 & \\
\hline Cirolanidae & 2.75 & & & & 2.65 & 2.69 & 2.93 & & & \\
\hline Gnathiidae & 2.50 & 1.96 & 3.74 & 2.57 & 3.01 & 2.35 & 2.93 & 2.57 & & 5.74 \\
\hline Serolidae & 1.52 & 2.87 & 2.67 & & 1.90 & 1.75 & 1.60 & 3.80 & 3.83 & 5.60 \\
\hline \multirow{2}{*}{\multicolumn{11}{|c|}{ TANAIDACEA }} \\
\hline & & & & & & & & & & \\
\hline $\begin{array}{l}\text { Tanaidacea unid. } \\
\text { EUPHAUSIACEA }\end{array}$ & 2.90 & 3.70 & 7.61 & 7.79 & 2.09 & & & 3.79 & 4.05 & \\
\hline Euphausiidae & 1.83 & 4.02 & 4.79 & 4.84 & 1.75 & 2.31 & 2.43 & 6.37 & 9.21 & 9.56 \\
\hline DECAPODA & & & & & & & & & & \\
\hline Hippolytidae & & & 3.78 & & & 1.93 & & 3.58 & & 7.33 \\
\hline Crangonidae & & & 3.14 & & & 1.28 & & 2.54 & & 5.04 \\
\hline
\end{tabular}

average dissimilarity for different combinations of pairwise groups of stations and only 4 taxa account for dissimilarities between any pairwise station groups: Mysidae, Gammaridea, Hyperiidea and Euphausiidae (Table 6). The highest dissimilarity values in the segregation of the pairwise stations groups were obtained for Mysidae (AE, CD and DE), Lysianassidae (AB, BC, $\mathrm{BD}$ and $\mathrm{BE})$, Gammaridea (AC) and Munnopsidae (AD and CE).

\section{Relationship between biotic and environmental variables}

The results of the BIO-ENV procedure applied to the biotic data and the selected abiotic variables are shown in Table 7. As a whole, the Spearman rank correlation values show low significance. The highest correlation is a combination of water depth with sediment mud content $(\rho=0.310)$. Particularly, depth is the variable matching the best result $(\rho=$ 
TABLE 7. - Result of BIOENV analysis to select the number of abiotic variables which best match the biotic matrix. Bold values indicate best matches. Variables: 1, depth; 2, Eh; 3, organic matter $(\%)$; 4 , gravel $(\%) ; 5$, coarse sand $(\%) ; 6$, medium sand $(\%)$; 7, fine sand $(\%) ; 8$, mud $(\%)$.

\begin{tabular}{lcc}
\hline Number of variables & Correlation & Selections \\
\hline 1 & $\mathbf{0 . 2 9 1}$ & 1,8 \\
2 & $\mathbf{0 . 3 1 0}$ & 1,2 \\
2 & 0.283 & 1,3 \\
2 & 0.273 & 1,5 \\
2 & 0.266 & $1,2,8$ \\
3 & $\mathbf{0 . 3 0 0}$ & $1,3,8$ \\
3 & 0.283 & $1,2,5$ \\
3 & 0.281 & 1,3 \\
3 & 0.264 & $1,5,8$ \\
3 & 0.263 & $1,2,6$ \\
3 & 0.260 & $1,3,5$ \\
3 & 0.249 & $1,2,5,8$ \\
4 & 0.281 & $1-3,8$ \\
4 & 0.278 & $1-3,5$ \\
4 & 0.264 & $1,2,6,8$ \\
4 & 0.255 & $1,3,5,8$ \\
4 & 0.251 & $1-3,6$ \\
4 & 0.243 & $1-3,5,8$ \\
5 & 0.269 & $1-3,6,8$ \\
5 & 0.245 & \\
\hline
\end{tabular}

0.291) when each abiotic variable is considered separately.

\section{DISCUSSION}

The BENTART-03 and BENTART-06 sampling programmes studied for the first time the suprabenthic assemblages from the Bellingshausen Sea and the western Antarctic Peninsula.

The 35 stations yielded at least 66 taxa at family level or higher, mainly amphipods, isopods, cumaceans, pycnogonids, decapods and mysids. Peracarid crustaceans represented $83.3 \%$ of the total number of taxa.

The suprabenthic fauna sampled in the study area was numerically dominated by peracarid crustaceans, of which amphipods were most numerous, followed by mysids, isopods, cumaceans and tanaidaceans, representing more than $96 \%$ of all collected individuals. The abundance and diversity of these motile crustaceans in the near-bottom environment demonstrate the existence of a suprabenthic habitat in Antarctic waters, as already mentioned by San Vicente et al. (1997) for the South Shetland Islands and in the Bransfield Strait.

The suprabenthic abundances showed a clear decreasing vertical gradient from the sediment-water interface to the uppermost water layer sampled by the Macer-GIROQ sledge. This vertical gradient was also observed in almost all taxa except for the euphausiids, which avoid close contact with the sea bottom. Such a near-bottom vertical distribution pattern is a typical feature of suprabenthic species of most marine areas (Mees and Jones, 1997), including Antarctic waters (Corbera, 2000; Ramos, 2003; San Vicente et al., 2006, 2007).

Although sampled in comparable near-bottom environments, the relative abundances of the major suprabenthic taxa (Mysida, Amphipoda, Cumacea, Tanaidacea and Isopoda) are highly variable according to the southern geographical regions investigated (Linse et al., 2002; Lörz and Brandt, 2003; Rehm et al., 2007; San Vicente et al., 2007). Variations in physical factors such as current direction and speed, sea-ice cover, sediment structure, topography and food supply may cause differences in the composition of suprabenthic assemblages from place to place in the Southern Ocean. Also, in agreement with Brenke (2005), we think that such a variability is partially due to distinct sampler performances and to more or less accurate estimates of towing distances on the sea floor.

The peracarid composition of southern deeper-sea areas (below $2000 \mathrm{~m}$ depth) shows distinct differences to that on the Antarctic shelf, especially in the increase of isopod dominance (Brandt et al., 2007a,b). Deeper BENTART 2003 and 2006 sampled stations (1000$2000 \mathrm{~m}$ depth) showed that Amphipoda, Mysida and Isopoda in decreasing order were the most abundant taxa. Our data support that the clear break observed in the peracarid faunal composition between shelf and deep sea in the Southern Ocean takes place in deeper waters than in other world oceans (Brökeland et al., 2007). This is probably the result of combined processes such as the depth of the Antarctic shelf due to the weight of the ice shield on the continent (Brökeland et al., 2007), the impact of the glacial periods on the development of a higher potential of eurybathy of Antarctic organisms (Brey et al., 1996), and the exchange between shallow and deep fauna and vice versa described as Antarctic submergence or emergence (Brandt et al., 2007a,b).

According to San Vicente et al. (2007), and to results of the present study, the highest suprabenthos abundances were always recorded in the lowermost $10-50 \mathrm{~cm}$ near-bottom water layer. Therefore, more realistic estimates of suprabenthos abundance are certainly obtained when samplings are carried out as close as possible to the sea floor, where motile crustaceans are known to concentrate at least during daytime. 
The mean suprabenthos abundances herein mentioned for the Bellingshausen Sea (206 ind./100 m² depth range: $85-3280 \mathrm{~m}$ ) are significantly lower $\left(\mathrm{U}_{\mathrm{obs}}=4.55, \mathrm{p}<0.001\right)$ than values reported from the western Antarctic Peninsula / Bransfield Strait (1908 ind./100 $\mathrm{m}^{2}$; depth range: $45-649 \mathrm{~m}$; San Vicente et al., 2007; same methodology as in this study). These results confirm that the Bellingshausen Sea is a vast 'benthic desert' driven by an oligotrophic regime (Mouriño, pers. comm.), as previously reported by Saiz-Salinas et al. (2008) for macro-infauna and by Ramil (pers. comm.) for epibenthos from the same geographical area (BENTART 03-06 cruises). According to their composition at family level, five main suprabenthic assemblages were detected in the study area, mainly structured by environmental features gradually changing with the depth gradient (sediment mud content). Assemblages were discriminated according to their taxa richness (decreasing values with depth gradient) and to the relative contribution of some dominant taxa such as amphipods (Lysianassidae, Oedicerotidae, Synopiidae), mysids (Mysidae, Petalophthalmidae), isopods (Munnopsidae, Cirolanidae, Gnathiidae), cumaceans (Nannastacidae) and euphausiids (Euphausiidae).

In accordance with their known demersal scavenging behaviour (De Broyer et al., 2001), the high contribution of Lysianassidae in suprabenthic assemblages from the study area, mainly in its deepest part $(16.3 \%$ and $12.4 \%$ of total abundance in the Bellingshausen Sea and Southwest Antarctic Peninsula samples, respectively; only $3.8 \%$ off the northwestern coast of the Antarctic Peninsula, San Vicente et al., 2007) suggests that this region of the Southern Ocean offers low-quality nutritive resources for detritivorous peracarids. In the study area, the multivariate analysis of data emphasised the role of two main structuring abiotic factors: the depth gradient and the mud content of surficial sediments. However, further unmeasured environmental and biotic factors such as epibenthic habitat complexity and predation impact may also be responsible for the observed distributions (De Broyer et al., 2001; Lörz and Brandt, 2003). Except for their coastal zones $<100 \mathrm{~m}$ depth (see Saiz-Salinas et al., 1997; Arnaud et al., 1998), the Bellingshausen Sea and western Antarctic Peninsula are characterised by soft bottoms, high sedimentation rates and low primary production, a situation that is exacerbated still further by the influence of physical disturbances (iceberg scouring). This benthic situation is quite different to those re- ported from the Weddell and Ross seas, where dense three-dimensional communities of long-lived filterfeeders have been described. The lack of such spatial complexity in benthic microhabitats could also be an important factor affecting suprabenthic assemblages in the Bellingshausen Sea and SW Antarctic Peninsula, as previously mentioned by San Vicente et al. (2007) for some suprabenthic communities from the South Shetland Islands and Bransfield Strait.

Physical disturbances linked to intense iceberg traffic (iceberg scouring over the sea-floor and fall of iceberg drop-stones onto the sea-floor) were frequently observed during BENTART cruises in the Bellingshausen Sea. Expected subsequent responses of the macrofauna communities were described by Saiz-Salinas et al. (2008) and Aldea et al. (2008). Furthermore, the presence of large stones (related to iceberg thaw) on the bottom renders benthos sampling in the Bellingshausen Sea difficult, especially in the case of drag-along samplers (Agassiz trawl and suprabenthic sledge). Such methodological difficulties may be responsible for suprabenthos underestimates at some sampling sites, as suggested also by Matallanas and Olaso (2007) concerning the demersal fish fauna of the Bellingshausen Sea.

The present contribution is the first attempt to describe poorly-known suprabenthic assemblages from remote marine Antarctic regions. Subsequent studies on the abundant suprabenthos material collected during BENTART cruises will focus on species identification to provide new data on their geographical and bathymetrical distribution as well as new structural analyses of assemblages at a detailed taxonomical level. From an ecological perspective, our main objective within the framework of the BENTART research programme is to obtain a better knowledge of marine biodiversity as well as a better understanding of assemblage organisation and related ecological processes occurring in these under-studied regions of the Southern Ocean.

\section{ACKNOWLEDGEMENTS}

The BENTART cruises were carried out under the auspices of the Spanish Government through the Ministry of Education and Science and were supported by the Spanish Antarctic Programme (CICYT) (REN2001-1074/ANT and CGL2004-01856). The crew and officers of RV Hesperides, and our colleagues from BENTART cruises 2003 and 2006 
played a vital part in the materialisation of this project at sea. J.L. Sánz, B. Mouriño and F. Ramil communicated useful comments on their own results related to BENTART investigations. To all of them we express our gratitude. A. Brandt, K. Linse and W.E. Arntz are also thanked for their comments and suggestions, which improved our manuscript.

\section{REFERENCES}

Aldea, C., C. Olabarria and J.S. Troncoso. - 2008. Bathymetric zonation and diversity gradient of gastropods and bivalves in West Antarctica from the South Shetland Islands to Bellingshausen Sea. Deep-Sea Res. I, 55(3): 350-368.

Arnaud, P.M., C.M. Lopez, I. Olaso, F. Ramil, A. Ramos-Espla and A. Ramos. - 1998. Semi-quantitative study of macrobenthic fauna in the region of the South Shetland Islands and the Antarctic Peninsula. Polar Biol. 19: 160-166.

Arntz, W.E., S. Thatje, D. Gerdes, J.M. Gili, J. Gutt, U. Jacob, A. Montiel, C. Orejas and N. Teixidó. - 2005. The Antarctic-Magellan connection: macrobenthos ecology on the self and upper slope, a progress report. Sci. Mar., 69(2): 237-269.

Brandt, A. - 1993. Composition, abundance, and diversity of peracarid crustaceans on a transect of the Kolbeinsey Ridge, north of Iceland. Polar Biol., 13: 565-576.

Brandt, A. - 1995. Peracarid fauna (Crustacea, Malacostraca) of the Northeast Water Polynya off Greenland: documenting close benthic-pelagic coupling in the Westwind Trough. Mar. Ecol. Prog. Ser., 121: 39-51.

Brandt, A. and D. Barthel. - 1995. An improved supra- and epibenthic sledge for catching peracarida (Crustacea, Malacostraca). Ophelia, 43(1): 15-23.

Brandt, A., C. De Broyer, I. De Mesel, K.E. Ellingsen, A. Gooday, B. Hilbig, K. Linse, M. Thomson and P. Tyler. - 2007a. The deep benthos. In: A. Rogers (ed.), Antarctic Ecology: From Genes to Ecosystems, Royal Society, London. Phil. Trans. R. Soc. B., 362: 39-66.

Brandt, A., A.J. Gooday, S.B. Brix, W. Brökeland, T. Cedhagen, M. Choudhury, N. Cornelius, B. Danis, I. De Mesel, R.J. Diaz, D.C. Gillan, B. Ebbe, J. Howe, D. Janussen, S. Kaiser, K. Linse, M. Malyutina, S. Brandao, J. Pawlowski and M. Raupach. - 2007b. The Southern Ocean deep sea: first insights into biodiversity and biogeography. Nature, 447: 307-311.

Brenke, N. - 2005. An epibenthic sledge for operation on marine soft bottom and bedrock. Mar. Tech. Soc. J., 39(2): 13-24.

Brey, T., C. Daham, M. Gorny, M. Klages, M. Stiller and W.E. Arntz. - 1996. Do Antarctic benthic invertebrates show an extended level of eurybathy? Antarctic Sci., 16(4): 559-568.

Brökeland, W., M. Choudhury and A. Brandt. - 2007. Composition, abundance and distribution of Peracarida from the Southern Ocean deep sea. Deep-Sea Res. II, 54: 1752-1759.

Cartes, J.E., J.C. Sorbe and F. Sarda. - 1994. Spatial distribution of deep-sea decapods and euphausiids near the bottom in the northwestern Mediterranean. J. Exp. Mar. Biol. Ecol., 179: 131-144.

Clark, K.R. and R.N. Gorley. - 2001. Primer v5: User Manual/Tutorial. Plymouth Marine Laboratory.

Corbera, J. - 2000. Systematics and distribution of cumaceans collected during Bentart-95 cruise around South Shetland Island
(Antarctica). Sci. Mar., 64(1): 9-28

De Broyer, C., Y. Scailteur, G. Chapelle and M. Rauschert. - 2001. Diversity of epibenthic habitats of gammaridean amphipods in the eastern Weddell Sea. Polar Biol., 24: 744-753.

Field, J.G., K.R. Clarke and R.M. Warwick. - 1982. A practical strategy for analysing multispecies distribution patterns. Mar. Ecol. Prog. Ser., 46: 7-12

Kaiser, S., D.K.A. Barnes, K. Linse and A. Brandt. - 2008. Epibenthic macrofauna associated with the shelf and slope of a young and isolated Southern Ocean island. Antarctic Sci., 20(3): 281-290.

Linse, K., A. Brandt, B. Hilbig and G. Wegener. - 2002. Composition and distribution of suprabenthic fauna in the south-eastern Weddell Sea and off King George Island. Antarctic Sci., 14(1): 3-10.

Lörz, A.N. and A. Brandt. - 2003. Diversity of Peracarida (Crustacea, Malacostraca) caught in a suprabenthic sampler. Antarctic Sci., 15(4): 433-438.

Matallanas, J. and I. Olaso. - 2007. Fishes of the Bellingshausen Sea and Peter I Island. Polar Biol., 30: 333-341.

Mauchline, J. - 1980. The biology of mysids and euphausiids. Advances in Marine Biology. Vol. 18: Academic Press.

Mees, J. and M.B. Jones. - 1997. The hyperbenthos. Oceanogr. Mar. Biol. Ann. Rev. 35: 221-255.

Ramos, A. - 2003. Biodiversidade bentónica das Illas do Arco de Scotia, Shetlands do Sur e Estreito de Bransfield (Antártica). $\mathrm{Ph}$. D. thesis, Univ. Vigo, Spain.

Rehm, P., S. Thatje, U. Mühlenhardt-Siegel and A. Brandt. - 2007. Composition and distribution of the peracarid crustacean fauna along a latitudinal transect off Victoria Land (Ross Sea, Antarctica) with special emphasis on the Cumacea. Polar Biol., 30: 871-881.

Saiz-Salinas, J.I., A. Ramos, F.J. Garcia, J.S. Troncoso, G. San Martin, C. Sanz and C. Palacin. - 1997. Quantitative analysis of macrobenthic soft-bottom assemblages in South Shetland waters (Antarctica). Polar Biol., 17: 393-400.

Saiz-Salinas, J.I., F.J. Garcia, M.E. Manjón-Cabeza, J.Parapar, A. Peñas-Cantero, T. Saucede, J.S. Troncoso and A. Ramos. - 2008. Community structure and spatial distribution of benthic fauna in the Bellingshausen Sea. Polar Biol., 31: 735-743.

San Vicente, C., A. Ramos, A. Jimeno and J.C. Sorbe. - 1997. Suprabenthic assemblages from South Shetland Islands and Bransfield Strait (Antarctica): preliminary observations on faunistical composition, bathymetric and near-bottom distribution. Polar Biol., 18: 415-422.

San Vicente, C., A. Ramos and J.C. Sorbe. - 2006. Suprabenthic euphausiids and mysids from the South Shetland Islands and the Bransfield Strait, Southern ocean (BENTART-95 cruise). Polar Biol., 29: 211-222.

San Vicente, C. J. Castello, J. Corbera, A. Jimeno, T. Munilla, C. Sanz, J.C. Sorbe and A. Ramos. - 2007. Biodiversity and structure of the suprabenthic assemblages from South Shetland Islands and Bransfield Strait, Southern Ocean. Polar Biol., 30: 477-486.

Svavarsson J, G. Gudmundsson and T. Brattegard. - 1993 Feeding by asellote isopods (Crustacea) on foraminifers (Protozoa) in the deep sea. Deep Sea Res., 40(6): 1225-1239.

Troncoso, J.S., C. Aldea, P. Arnaud, A. Ramos and F. Garcia. - 2007. Quantitative analysis of soft-bottom molluscs in the Bellingshausen Sea and around Peter I Island. Polar Res., 26: 126-134.

Scient. ed.: W.E. Arntz.

Received June 19, 2008. Accepted November 20, 2008.

Published online March 4, 2009. 